\title{
Structure-Based Algorithm for Presentation Mapping in Graphical Knowledge Display
}

\author{
Vinothini Kasinathan, Aida Mustapha, and Mohamad Firdaus Che Abdul Rani
}

\begin{abstract}
Slide presentations have been widely used in current teaching and learning process. While text-laden slides might give a comprehensive feel over the materials, information overload might end up the learner getting confused in the middle of presentation. On the contrary, slides full of key points are not useful without the presenter. The objective of this research is to improve the teaching and learning process by transforming the slide content into a graphical knowledge display. A structure-based algorithm for presentation mapping is proposed to extract the keywords from each slide and to model into a mind map via web interface.
\end{abstract}

Index Terms-Presentation mapping, mind map, concept map, text mining.

\section{INTRODUCTION}

Widespread use of slide-based presentation using presentation program such as the Microsoft PowerPoint provide a healthy diet of visual stimulation that will help users to make a clear, compelling presentation. PowerPoint was introduced by Microsoft as a proprietary commercial software presentation program back in 1990 for users to create a professional looking presentation in business. It is estimated that 30 million PowerPoint presentations are delivered every day [1].

In education, collection of the data that displays in a graphical format with the characteristic of lesser text, colorful pictures or shapes may assists the learner in enhancing their memory [2] and understanding [3]. Nonetheless, we believe the use of slide-based presentation is overemphasized, whereby the old adage "A picture is worth a thousand words" does not hold true anymore. While images or keywords should save the instructor from speaking a paragraph of descriptive details, the slide does not only fit visual images to the oral presentation, but is laden with text.

This has led to conditions such as PowerPoint poisoning that refers to excessive use of words in each content slide with more than five bulleted points per slide [4]. If this is the case, then the instructor would spend more than five minutes for one slide, hence triggering the learner to starts reading instead and ending up not listening to the explanation delivered.

Another condition is myopia, when the content is designed

Manuscript received September 15, 2012; revised December 29, 2012.

V. Kasinathan and A. Mustapha are with the Faculty of Computer Science and Information Technology, Universiti Putra Malaysia, Selangor, Malaysia ( e-mail: vinothini@apu.edu.my, aida@fsktm.upm.edu.my).

M. F. C. A. Rani is with Asia Pacific University of Technology and Innovation, Kuala Lumpur, Malaysia (e-mail: firdaus@apu.edu.my). using contrasting colors or a font size that is too small. This will lead to confusion among learners, by not knowing which the important points are. At the end of the spectrum is the presentation death to the learners after long-suffering from reading word-for-word from the visual slide.

While text-laden slides might give a comprehensive feel over the materials, such information overload might end up the learner getting confused in the middle of presentation. Learners will also find difficulty in understanding the slide when the presentation session is over. Without the presenter, slide-based presentation may lead to misunderstanding because a good slide will contain less explanation but full of key points. This will obviously put the learners at loss.

When such conditions take place, the quality of teaching and learning will be greatly affected because today's learners across primary to tertiary education are part of a generation called the digital natives [5]. Massive literature digital natives were based on the premise that their brains are built differently as compared to the older generations, which are referred to digital immigrants.

According to Prensky [5], digital natives are people who are born after the technological era of $21^{\text {st }}$ century as opposed to the digital immigrants who were born in the 20th century. Digital natives are also nuanced by alternative terminologies such as the gen-Y, net-gen [6], digital generation [7], millennial generation [8], and dot.com generation.

According to Bayne and Ross [9], today learners are immersed in digital technologies. They highly rely on computers and Internet for their daily activities. With the ability for multi-tasking, they crave for speed of access and instant gratification. This group of learners will usually not be able to recall the lecture delivered as taking notes is not part of their in-class regime anymore. They grew up in a highly stimulating and interactive digital environment; hence they are not accustomed to being passive receptors, in particular being an audience to lecture with slide-based presentation.

The remainder of this paper will proceed as follows. Section II will introduce graphical knowledge display in general. Section III will present the proposed Presentation Mapping, which includes the new structure-based algorithm, Section IV will demonstrate implementation of presentation mapping, while Section V concludes with some indication of future work.

\section{GRAPHICAL KNOWLEDGE DisPlay}

When slide-based presentation does not interest today's crowd, new pedagogical tool using graphical knowledge display such as the mind map is explored [10]. According to 
Kinchin [3] research has shown that slide-based presentations such as using PowerPoint are usually prepared by the subject matter expert or packaged as book companion. The integrated knowledge structure of the subject matter expert is transformed into presentation slides, which are in linear sequence. Nonetheless, after the presentation delivery, the teaching sequence is reconstructed differently by the learners [3]. Misinterpretation of the original expert structure (original contents of the slides) by the instructor in their teaching sequence and different student reconstruction is illustrated by Fig. 1 .

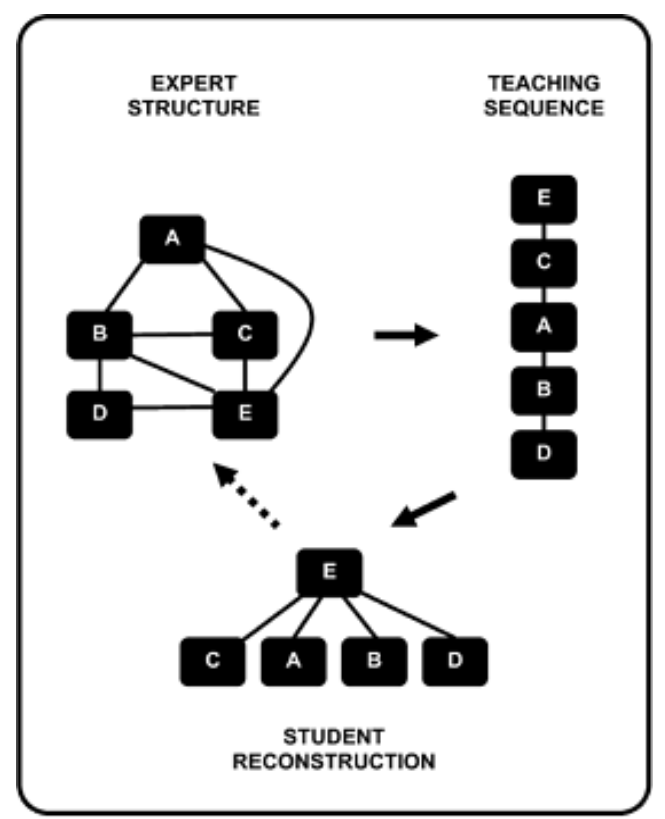

Fig. 1. The transformation cycle from integrated knowledge structure into a linear sequence [3].

In line with this view, Kinchin [11] proposes concept mapping to help learners visualize the content hence shifting the focus from linear structure to network of expert knowledge. Concept mapping have been widely adopted in academic teaching in general and computer-based education in particular [12], [13]. It is commonly used to organize and represent tacit knowledge with general concepts at the top of the map and more specific concepts arrayed hierarchically below. Connector lines usually contain keywords or phrases that summarize the relationship between the topics they connect, for example topic A "causes" topic B. Topics in concept maps may be cross-linked with each other to depict more complex relationships between topics.

Another similar pedagogical tool is mind mapping. A mind map is a type of graphical knowledge display used to visualize outline information popularized by Buzan [14]. His research promotes mind map as the ultimate organized thinking tool because Buzan justifies that average human only uses less than $1 \%$ of their brain in the areas of creativity, memory and learning. This finding is supported by Zhang et al. [15] who promotes mind map as a tool to enhance memory and is an excellent method for aiding human memory because it utilizes both left and right brain.

Mind mapping is different from concept mapping because topics in mind maps may only have one parent while in a concept map, a topic may have multiple connector lines. Mind mapping tends to be more flexible and personal as compared to concept maps because it slices and dices the map's central topic or concept in multiple ways as designed by the owner. Mind maps also promote use of images and colors to make them more visually stimulating. The structure of a mind map is also simplified from a concept map by having only one central key [13], hence they claim that a mind map is actually more effective when applied to written materials [2].

According to Davies [13], the main purpose for software mapping tools such as for concept mapping or mind mapping is to help the presenter or lecturer impart critical and analytical knowledge to students hence enabling the students to see relationships between concepts. Common features of such tools include different representation of diagrammatic relationships in preference to written or verbal descriptions. This research concludes that pictures and structured diagrams are more comprehensible than just words, and provide clearer way to illustrate understanding of complex topics.

Nonetheless, the terms concept mapping and mind mapping are often used interchangeably in the literature. In addition, the techniques for concept mapping or mapping is not obvious even to the digital natives, therefore it has to be trained. Constructing mind map manually required good understanding, effort and time, as well as good imagination and understanding on the subject matter [16].

To facilitate process of constructing the mind map, we propose a technique to automatically extract the structure of a slide-based presentation and reconstruct the structure in the form of a mind map.

\section{Proposed Presentation MapPing}

Variety of software packages has been developed and introduced into the education domain to tailor learning characteristics of the digital natives. To iterate the point by Davies [13], concept maps or mind maps are difficult to interpret by others and have limited capabilities when dealing with complex relationship. The construction is time-consuming because it is essential for students to understand the main concept beforehand. This implies concept mapping or mind mapping requires expertise to develop, but the complexity does not assist in memorability. At the end, such applications can be overwhelming and demotivating because of its many rules and multiple relationships to learn [17], [18].

In this paper, we introduce the term "Presentation Mapping" as an automated technique to extract keywords from lecture slides and present the keywords in a graphical knowledge display with relationships among the individual slides. The proposal is motivated by the problem of not knowing how to draw a mind map or a concept map among the university students, despite the fact that most lecture materials at the university level is in slide-based format.

Fig. 2 shows the proposed architecture for presentation mapping. Based on this figure, the architecture is divided into two sections, which are the client side and the server side. The client side has a web interface and is marked with process 1 and process 4 . The process begins with (1) uploading the PowerPoint slide, (2) applying the presentation mapping algorithm to filter and extract the keywords into text 
files, (3) generating the mind maps, and finally (4) displaying the maps.

Meanwhile, tasks carried out on the server side are marked with process 2 and process 3. Process 3 in particular extracts the content of PowerPoint slides based and then redraw in the form of presentation map using the structure-based presentation mapping techniques suggested in the paper.

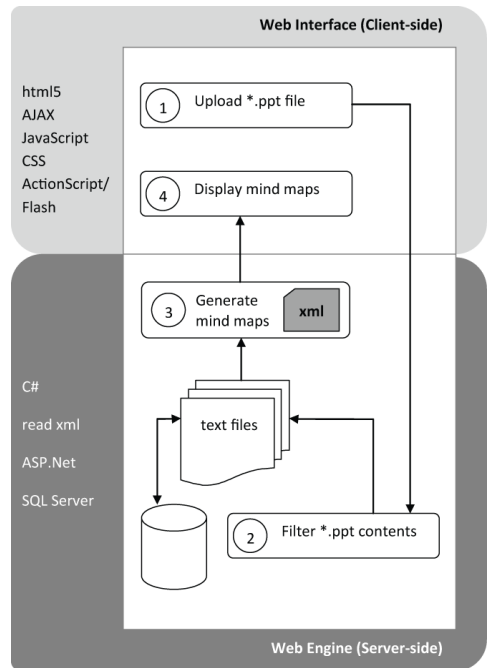

Fig. 2. Architecture for presentation mapping.

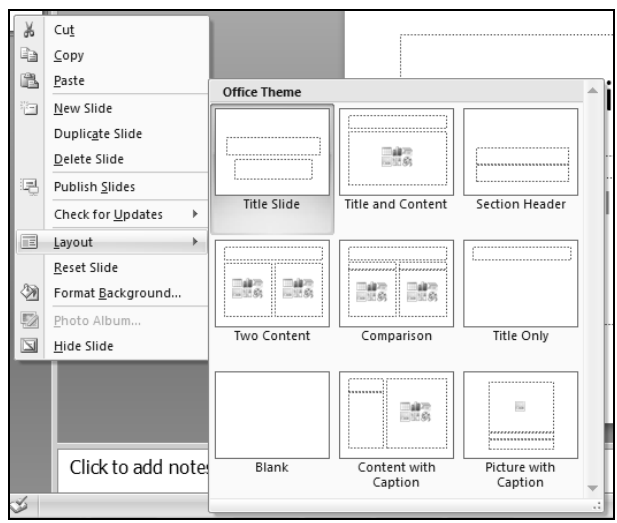

Fig. 3. Layout selection in powerpoint.

In order to generate text into a mind map, we need an algorithm that will identify and extract the text based on information specific to standard presentation slides such as the layout. In this research, we propose a structure-based algorithm that associates the presentation layout with the important keywords. Basically, the proposed algorithm takes PowerPoint slide as the text source and generates the map as an output.

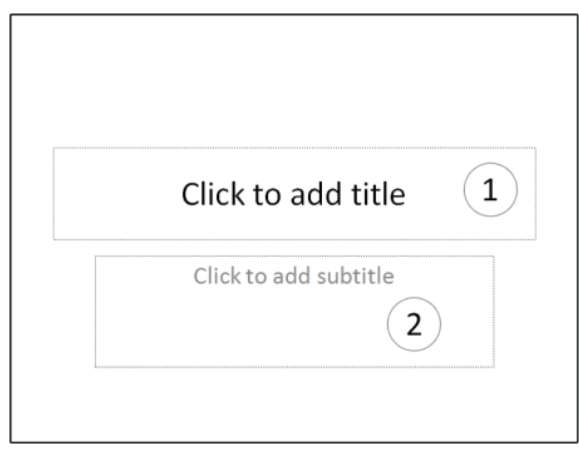

Fig. 4. Basic structure of 'Title Slide' layout.

In PowerPoint, there are nine slide layouts in total as shown in Fig. 3. However, this research focuses on two main layouts, which are 'Title' layout and 'Title and Content' layout. This is because both layouts involve text structure without any other object like image, video or animation.

Next, Fig. 4 and Fig. 5 show the structure of PowerPoint in the 'Title' slide layout and 'Title and Content' layout, respectively.

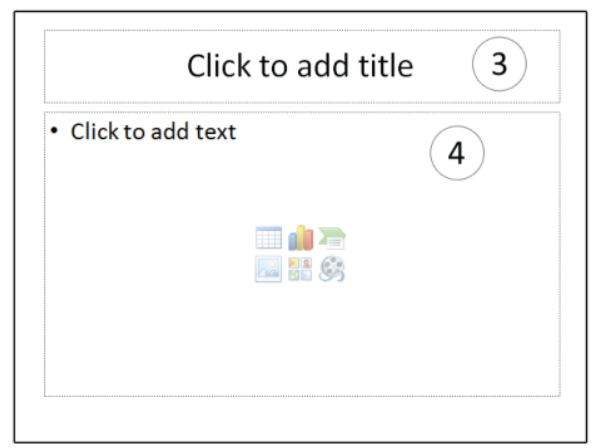

Fig. 5. Basic structure of 'Title and Content' layout.

Based on the layout available, Table I and Table II summarize the font and text attributes in both layouts.

TABLE I: SUMMARY OF TEXT/ FONT ATTRIBUTES OF ‘TITLE SLIDE’ LAYOUT

\begin{tabular}{|l|l|l|}
\hline Attributes & Section (1) & Section (2) \\
\hline Font size & $44 \mathrm{pt}$ & $32 \mathrm{pt}$ \\
\hline Font weight & Bold & - \\
\hline Letter case & $\begin{array}{l}\text { ALL UPPERCASE } \\
\text { Sentence case } \\
\text { Capitalize Each Word }\end{array}$ & Sentence case \\
\hline Bullets and numbering & - & - \\
\hline
\end{tabular}

TABLE II: SUMMARY OF TEXT/ FONT ATTRIBUTES OF ‘TITLE AND CONTENT' LAYOUT

\begin{tabular}{|l|l|l|}
\hline Attributes & Section (3) & Section (4) \\
\hline Font size & $44 \mathrm{pt}$ & $\begin{array}{l}\text { Main point: 32pt } \\
\text { Sub point: 28pt } \\
\text { Level 1: 24pt } \\
\text { Level 2: 20pt }\end{array}$ \\
& & Bold (keyword) \\
\hline Font weight & Bold (keyword) & Sentence case \\
\hline Letter case & Sentence case & $\begin{array}{l}\text { Bullet } \\
\text { Numbering available }\end{array}$ \\
\hline Bullets and numbering & $\begin{array}{l}\text { Bullet } \\
\text { Numbering available }\end{array}$ & \\
\hline
\end{tabular}

IF file_type EQUALS TO *.ppt OR*.pptx OPEN file READ slide_no READ text READ font_size IF slide_no EQUALS TO 1 IF font_size MORE THAN OR EQUAL TO 34 AND LESS THAN OR EQUAL TO 44 ASSIGN text to ppt title WRITE "title" + ppt_title ELSE IF font_size MORE THAN OR EQUAL TO 22 AND LESS THAN OR EQUAL TO 32 ASSIGN text to ppt_subtitle WRITE "_subtitle_" + ppt_subtitle ELSE IF font_size MORE THAN OR EQUAL TO 34 AND LESS THAN OR EQUAL TO 44 ASSIGN text to main_content WRITE "_mainContent_" + main_content ELSE IF font size MORE THAN OR EQUAL TO 22 AND LESS THAN OR EQUAL TO 32 ASSIGN text to sub content WRITE "_subContent_" + sub_content

ELSE

DISPLAY "Only PowerPoint file allowed"

Fig. 6. Proposed presentation mining algorithm. 
Given the font and text attributes from Table I and Table II, we propose a presentation mapping algorithm as shown in Fig. 6 to identify and extract the keywords. Other important attributes that are used to highlight keywords include font weight, use of bullets, numbering as well as letter case.

\section{IMPLEMENTATION}

A web interface with a file upload function is developed for the user to upload the PowerPoint file. This interface is also equipped with common validation steps such as checking the correct file type. The interface is shown in Fig. 7.

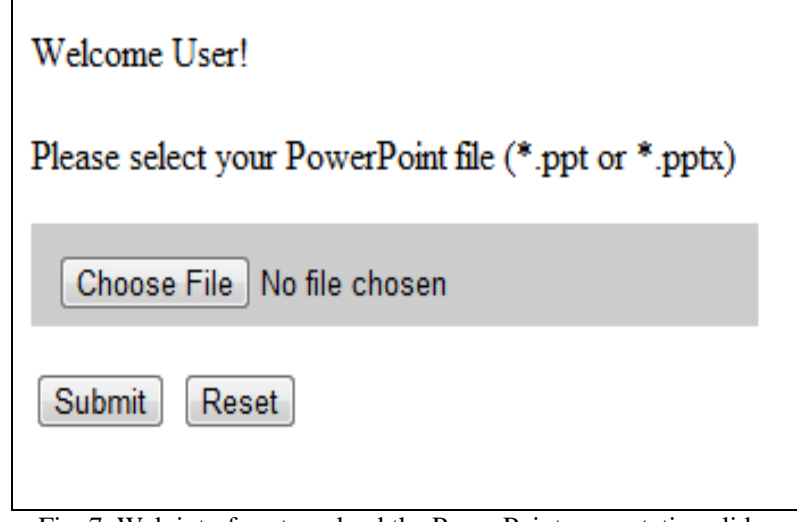

Fig. 7. Web interface to upload the PowerPoint presentation slide.

Back to process 1 in Fig. 2, the user is presented with an interface to upload the PowerPoint file into the server. When user clicks the Submit button, the extracted mind map will be shown in another frame as indicated by process 4 in Fig. 2. Fig. 8 shows sample of PowerPoint slides is uploaded to the system. In the slide with title 'Characteristics', there are three words that are bolded. This indicates highlights to keywords that are important to the materials in the presentation slides.

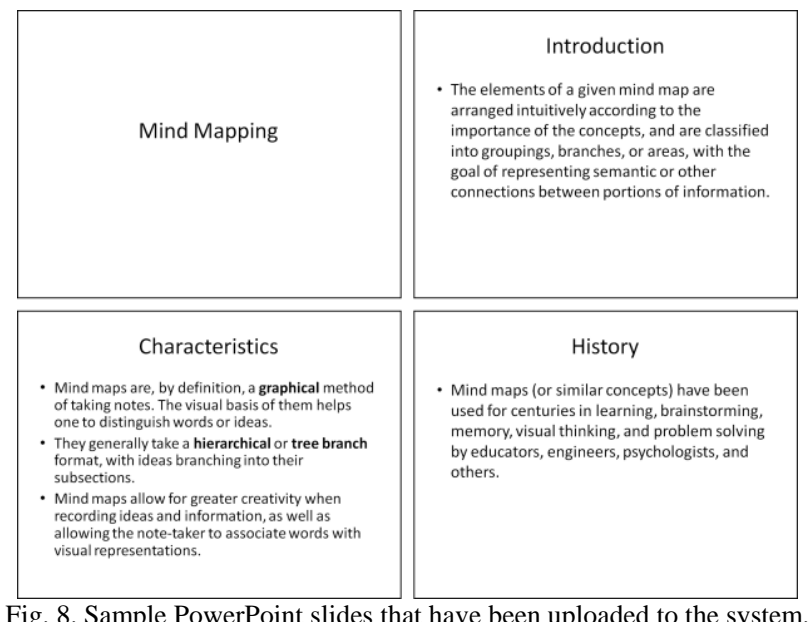

Next, Fig. 9 shows the resulting presentation mapping produced based on information extracted from slides in Fig. 8. From Fig. 9, we can see the main topic is chosen as the center of the concept map, followed by three first-level branches; Introduction, History, and Characteristics. Further, three keywords that are found highlighted bold in the third slide are also added as sub-branches within the branch Characteristics.

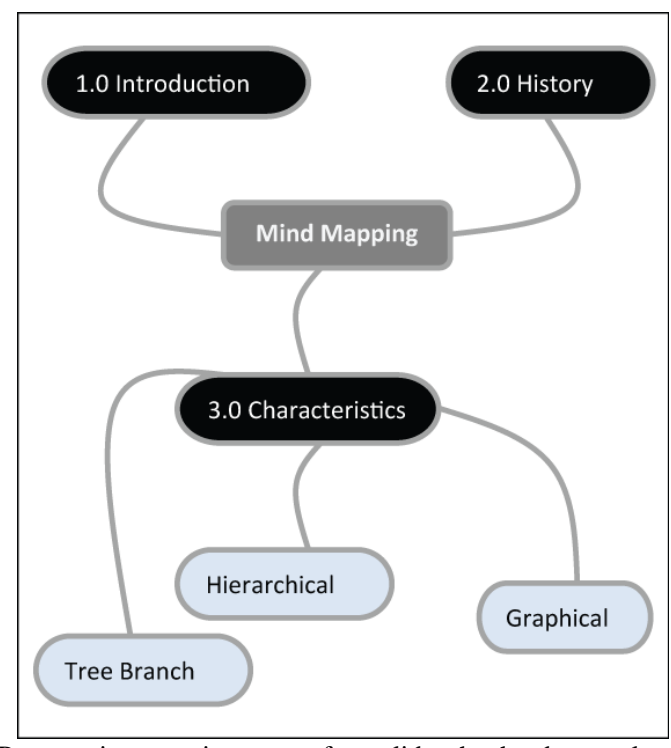

Fig. 9. Presentation mapping output from slides that has been uploaded from Fig. 8.

\section{CONCLUSION}

This paper has given a detailed account for a presentation mining algorithm that transforms content in a PowerPoint slide into mind maps, which is then used as a pedagogical tool for learning. This is in response to deteriorating effectiveness in slide-based PowerPoint presentation used by the generation of digital natives.

For future work, based on the proposed structure-based algorithm to map the presentation slides into mind map or concept map, we will also investigate what we call semantic-based approach. Recall that evidence from cognitive science has shown that graphical display does enhance learning [19]. The proposed Presentation Mapping algorithm is hoped to be used as part of teaching and learning tool among students and lecturers alike.

\section{REFERENCES}

[1] D. Paradi. (2006). What Annoys Audiences about PowerPoint Presentations? Ezine Articles. [Online]. Available: http://www.ezinearticles.com/?What-Annoys-Audiences-About-Powe rPoint-Presentations?\&id= 236985 .

[2] P. Farrand, F. Hussain, and E. Hennessy. (May 2002). The efficacy of the 'mind map' study technique. Medical Education. [Online]. 36(5). pp. 426-431. Available: http://www.onlinelibrary.wiley.com/doi/10.1046/j.1365-2923. 2002.01205.x/pdf

[3] I. M. Kinchin, D. Chadha, and P. Kokotailo, "Using PowerPoint as a Lens to Focus on Linearity in Teaching," Journal of Further and Higher Education, vol. 32, no. 4, pp. 333-346, 2008.

[4] J. Mckenzie. (September 2000). Scoring Powerpoints. The Educational Technology Journal. [Online]. 10(1). Available: Available: http://www.fno.org/sept00/powerpoints.html

[5] M. Prensky. (October 2001). Digital Natives. Digital Immigrants. On the Horizon. [Online]. 9(5). Available: http://www.marcprensky.com/writing/prensky\%20-\%20digital\%20nat ives, \%20digital\%20immigrants\%20-\%20part1.pdf.

[6] D. Oblinger. Boomers \& Gen-Xers Millennials Understanding the New Students. Educause Review. [Online]. 38(4). pp. 37-47. Available: http://www.iml2.usc.edu/wp-content/uploads/2012/04/BoomersGenX ersMillenials.pdf. (2003).

[7] C. Monereo. The virtual construction of the mind: the role of educational psychology. Journal of Interactive Educational Multimedia. [Online]. 9 pp. 32-47. Available: http://www.greav.ub.edu/der/index.php/der/article/ view/81/168, November 2004 
[8] N. Howe and W. Strauss, Millennials Rising: The Next Great Generation, New York, USA: Vintage Original, ch. 5, pp. 78-80, 2000

[9] S. Bayne and J. Ross, "The 'digital native' and 'digital immigrant': a dangerous opposition," presented at the Annual Conference of the Society for Research into Higher Education (SRHE), December, Brighton, Sussex, December 11-13, 2007.

[10] M. N. Ismail and K. A. Jalil, "Mind Mapping with Cooperative Learning in Supplementing Computer Programming Learning: Theoretical Framework," MASAUM Journal of Basic and Applied Sciences, vol. 1, no. 3, pp. 497-504, 2009

[11] I. M. Kinchin, "A Knowledge Structures Perspective on the Scholarship of Teaching \& Learning," International Journal for the Scholarship of Teaching and Learning, vol. 3, no. 2, pp. 1-6, July 2009.

[12] J. J. Villalon and R. A. Calvo, "Concept Map Mining: A Definition and a Framework for Its Evaluation," presented at IEEE/WIC/ACM International Conference on Web Intelligence and Intelligent Agent Technology, Sydney, Australia, December 9-12, 2008.

[13] M. Davies. Concept mapping, mind mapping and argument mapping: what are the differences and do they matter? Higher Education [Online]. 62(3). pp. 279-301. Available: http://www.rd.springer.com/article/10.1007/s10734-010-9387-6/fullte xt.html. September 2011.

[14] T. Buzan, B. Buzan, and J. Harrison, The Mind Map Book: Unlock Your Creativity, Boost Your Memory, Change Your Life, Harlow, England.: Pearson 2010, ch. 3, pp. 25-28.

[15] Z. Yan-Lei, "Mind Mapping Based Human Memory Management System," presented at International Conference on Computational Intelligence and Software Engineering (CiSE), Wuhan, China, December 10-12, 2010.

[16] R. El-Sahan, A. Ismaeil, S. El-Harouny, M. Shalaby, and M. C. E. Yagoub, "Direct automatic generation of mind maps from text with $\mathrm{M}^{2} \mathrm{Gen}$," presented at the Science and Technology for Humanity (TIC-STH), 2009 IEEE Toronto International Conference, Toronto, Canada, September 26-27, 2009.
[17] I. M. Kinchin, "If concept mapping is so helpful to learning biology, why aren't we all doing it?" International Journal of Science Education, vol. 23, no. 12, pp. 1257-1269, 2001

[18] M. J. Eppler, "A comparison between concept maps, mind maps, conceptual diagrams, and visual metaphors as complementary tools for knowledge construction and sharing," Information Visualization, vol. 5, pp. 202-210, 2006.

[19] I. Vekiri. (September 2002). What is the value of graphical display in learning? Educational Psychology Review. [Online]. 14(3). pp. 261-312. Available: http://www.deepblue.lib. umich.edu/bitstream/2027.42/44453/1/10648_2004_Article_374334.p df.

Vinothini Kasinathan is a lecturer at Asia Pacific University of Technology and Innovation (APU), Malaysia. She obtained her MSc. Computer Science and majored in Real Time Software Engineering from the University Technology Malaysia. She has been in Academic industry more than 10 years of working experiences as lecturer. Her research interest includes educational technology, text mining and concept mining. Presently she is pursuing her PhD. with University Putra Malaysia, Malaysia.

Aida Mustapha received the B.Sc. degree in Computer Science from Michigan Technological University and the M.IT degree in Computer Science from UKM, Malaysia in 1998 and 2004, respectively. She received her Ph.D. in Artificial Intelligence focusing on dialogue systems. She is currently an active researcher in the area of Computational Linguistics, Text Mining, and Agent Systems in Social Networks.

Mohamad Firdaus Che Abdul Rani is a lecturer at Asia Pacific University of Technology and Innovation (APU), Malaysia. His research interest includes Semantic Web, Web Accessibility and Knowledge Management. 